\title{
Outsourcing the hand: An analysis of craft-design collaborations across the global divide
}

\author{
By Kevin Murray
}

Dr Kevin Murray is Adjunct Professor RMIT University, Research Fellow University of Melbourne and Adjunct Research Fellow Monash University. $\mathrm{He}$ is currently online editor for the Journal of Modern Craft and coordinator of Southern Perspectives, a south-south intellectual network.

Abstract: This paper identifies a growing trend in contemporary craft practice which involves outsourcing handmade processes to artisans in poorer countries. To evaluate this process, it reviews three case studies: Sara Thorns Worldwide Weave in India, Polly\&Me in Pakistan, and Martina Dempf in Rwanda. Each enables different levels of creative collaboration with traditional artisans. While a critical framework is able to be established, there is still a lack of information that comes directly from the artisans themselves.

\section{Introduction}

This paper explores the continuing voice of craft as a critic of modernity that draws from non-Western cultures for inspiration. This has become an increasing politicised position in recent years. In response, world craft projects have highlighted the more collaborative dimension of production. But what is the nature of collaboration when it involves parties from radically unequal parts of the world?

Since the nineteenth century, craft in the West has been associated with opposition to modernity. Studio craftspersons looked for inspiration to other cultures that were innocent of the alienation found in the West (de Waal, 2002). Through non-western cultures it was possible to re-connect with the spiritual dimension of work, particularly its basis in the natural world.

In time, this engagement has become less spiritual. A feature of globalisation in the post-war era is the lengthening of supply chains. This is particularly evident in manufacturing, where much factory work has been outsourced to countries such as China. Recently, a new form of cultural outsourcing has emerged in which the non-West is not merely a source of inspiration, but also actual 'handson' craft labour. What are the terms of this engagement and what does this say about the place of craft in modernity? 
The Arts \& Crafts Movement was inspired by a reaction against modernity. As William Morris pronounced in his 1894 lecture 'How I became a socialist', 'Apart from the desire to create beautiful things the leading passion of my life has been and is hatred of modern civilization' (Morris, 1980, p. 36). Morris thus turned away from the grimy industrial Victorian England to idealised versions of pre-modernity, such as medieval England. In terms of his own time, it was the Nordic cultures, particularly Iceland, which provided inspiration through his own travel. ${ }^{1}$

In the 20th century, inspiration for the craft movement moved to the East. For Bernard Leach (1978, p. 187), the West had largely abandoned its 'laborious hand-methods'. Fortunately, according to Leach, there was in the scene of Japanese ceramics, particularly in the Mingei movement, an opportunity to revive the 'honest' spirit of craft. $^{2}$ Led astray by visual art, it was thought that ceramicists aspired to make unique works of art rather than authentic multiples involving repetitive craft processes. By connecting with this Zen spirit, Westerners could liberate themselves from the false path of individualism. ${ }^{3}$

Leach's orientalism in Western ceramics echoes the history of primitivism in visual art. Primitivism provided modern art with a scenario for stripping away tradition to reveal life in the raw underneath (Goldwater, 1986). Yet the association of non-Western cultures with a natural existence contained the seeds of its undoing (Foster, 1985). While it may initially be a matter of symbolic opposition to modernity, eventually those whose identities are associated with primitivism become actively involved in the contestation of the Western paradigm. Eventually, real people emerge from behind the African masks. The postcolonial critique argues that the so-called primitive subject of Africa and beyond must now be seen to have an active agency and voice in determining his or her own world (Araeen, 1987). Thus the symbolic challenge of primitivism in modernity eventually becomes a matter of real- world ethics. This paper follows a parallel development in the modern craft movement. ${ }^{4}$

By comparison with visual art, the world craft scene has a history of solidarity between West, East, North and South. In the 20th century, this solidarity is mediated by institutions such as the World Craft Council and UNESCO. During this period, the prevailing ideology was a humanism which positioned craft

1 William Morris claimed that 'Iceland was his "Holy Land."' (MacCarthy, 1994, p, 309).

2 There are two parts to each of us: the surface man who is concerned with pose and position, who thinks what he has been taught to think; and the real man who responds to nature and seeks life in his work. Bernard Leach (1976, p.17).

3 In Beyond East and West (1978, p.81), Leach responds to a letter from Yanaga that the symbolism of Zen reflects a negative mysticism reflected in denial of ego: 'Nearly all mysticisms take the negative way to reach a comprehension of the final unity.'

4 This focus the political dimension of collaborations in this paper does exclude aesthetic considerations. For instance, I don't consider the way these collaborations might introduce new techniques or forms into Western textile practice. This is not to deny the place of aesthetic values in the critical assessment of collaborative practice, though they are more difficult to demonstrate in academic discourse. An aesthetic dimension is still necessary to save the work from being seen as purely politics by proxy. 
against the mechanical reasoning of the modern West. Octavio Paz (1974, p. 24) contrasted the speed of technology with 'the heartbeat of human time' in craftsmanship. Paz's narrative informed the biennial meeting and exhibition of the World Craft Council in 1974. Since then, there is a natural alignment with world craft and the focus on cultural heritage supported by organisations like UNESCO. Such bodies argue for the need to support cultural traditions that are endangered by modern phenomena such as globalisation.

Reflecting the emergence of fields such as 'world music' (Feld, 2000), 'world craft' has involved projects that are ostensibly designed to benefit the artisan community. But even though craftspersons around the world are represented through international bodies, it is still rare to hear the voice of the artisan him or herself.

\section{Globalisation}

The process of globalisation has accelerated the decline of manual labour in the West. Increasingly manufacturing has outsourced its production to countries such as China (Chossudovsky, 2003). The most prominent areas include clothing and call centres. But in recent times, we are beginning to see this occurring in Western craft practice.

The idea of a craftsperson outsourcing their production would seem anathema to figures like Bernard Leach. For Leach, the process of making was intrinsic to the creative development of the craft form. Today the integrity of the craftsperson may be seen to be threatened not only by visual art, but also design. Within the design paradigm, the craftsperson abstracts his or her production so that it can be manufactured, freeing them from exactly the manual engagement that Leach saw as intrinsic to the spirit of craft.

There is an implied alternative narrative that conceives a developmental framework for craft, whereby a maker eventually ascends to the position of designer. As designer, they can focus on the critical decision-making process about products, rather than its mere execution on the bench. This craftsperson is a 'designer in waiting', as in the example of Marc Newson who began as a jeweller before becoming a globally successful designer. On a macro- economic level, this aspirationalism is supported by the notion of a 'smart nation' that develops its design capacity while leaving manufacturing to countries where the wages are cheaper.

The globalisation framework has been contested in the 21st century by a number of movements. The Slow Movement, originating in Italy, upheld the value of local produce and skills as against an industrialised consumerism that erased meaningful differences between time and space (Petrini, 2005; Parkins \& Craig, 2006). This reaction against consumerism has recently taken a more political expression through emergence of ethical consumerism (Auger et al., 2007). From a more collectivist perspective, the Fair Trade movement has sought to 
connect consumers with the lives of producers, particularly in commodities such as chocolate and coffee. This has begun to expand to the production of craft products (Lyon, 2006).

Meanwhile, globalisation has impacted negatively on traditional crafts. In many cases, the local market for such crafts is eroded due to the availability of cheap imported alternatives. This has left many traditional crafts in an unsustainable position. One remedy involves finding alternative markets for these products, where they will be valued for their symbolic importance rather than practical function (Hareven, 2003). These markets are located most often in Western cities.

To enable this connection, it is important to modify the crafted objects to meet the tastes of a predominantly urban audience. This provides a role for an external designer to assist traditional artisans in the development of their product so that it will succeed in this new wealthier market. UNESCO has supported this strategy with the publication in 2007 of Designers Meet Artisans, including case studies where traditional craft have been revived through product development. ${ }^{5}$

From the designer's perspective, this also reflects growing philanthropic values in design. High profile design 'gurus' like Philippe Starke have made public confessions which admit that their previous work was a negative force in the world, supporting meaningless consumption. ${ }^{6}$ Programs like the CooperHewitt's Design for the Other $90 \%$ encourage a view that design practice can also provide benefits for the poor countries of the world.

Alongside this have been designers who have developed practices and companies that develop and market craft product from poorer countries. The North South Project, founded by Canadian Patty Johnson, launched at the 2006 New York's International Contemporary Furniture Fair a range of product sourced from artisans in Botswana and Guyana. Such products are marketed as extending 'its reach across a global north/south axis' combining northern design intelligence with southern craft traditions. ${ }^{7}$

Such developmental design projects follow the Arts and Crafts movement to increased engagement with non-Western communities. However, the designers do not immerse themselves in those traditions in the same way that craftspersons like Bernard Leach worked in Japanese potteries. The relation between designer and artisan is closer to the business relationship between Western company and Chinese factory, though in many cases the ultimate goal is the benefit of the producer rather than the profit of the company.

5 http://portal.unesco.org/culture/en/ev.php-URL_ID29594\&URL_DODO_TOPIC\&URL_ SECTION201.html

6 See talk http://www.ted.com/talks/philippe_starck_thinks_deep_on_design.html from March 2007

7 http://www.northsouthproject.com 


\section{Outsourcing}

Outsourcing craft raises a number of critical questions. Ostensibly such projects are presented as being for the benefit of the producer. ${ }^{8}$ While there may be minimal conditions such as specified by Fair Trade that are fulfilled in these projects, it leaves open the broader question of ultimate benefit. Given the demand for such products in the West, what guarantee is there that such enterprises have not been constructed purely for the Western gaze (de Waal, 2002)? Critics of Fair Trade (Scrase, 2003; Lyon, 2006) argue that such gestures only mask the deeper inequities that are largely unaltered by these ameliorative projects. Which of the consumers would swap their comfortable lives for the drudgery of a craft workshop?

There are also questions from the consumer's perspective. What is the nature of the pleasure that a consumer gains in buying world craft? There is enjoyment related to craft per se, such as tactile stimulation, admiration of craftsmanship, connection with the meaning of the work. But intrinsic to much world craft is a framing narrative that traces such pleasures to the margins of modernity. This can engage with the romantic notions of a community untouched by the degradations of industrial society. Such craft offers an antidote to weakened social ties, disconnection from the physical world and disenchantment. Even further, in purchasing the product, the consumer is invited to feel a sense of solidarity with the producer in their opposition to the crass world of global capitalism.

But these are perceptions of perceptions. What are the critical standards by which we might evaluate the craft-design collaborations that produce world craft? From the artisan's angle, we might expect that the work is the free and spontaneous adaptation of traditional craft to the opportunities provided by a global market. In this case, the process of engaging with a global market is seen ideally as an exciting creative challenge for the artisans, which helps bridge the gap between past and future. The alternative is for such production to be driven purely by external market forces, similar to the 'sweatshop' arrangement in other export industries.

But we need to take into account the reciprocal perspective as well. What does this mean for the development of Western craft practices? How can we incorporate the outsourcing that occurs in the development of product into the creative field of the Western designer- maker? How can philanthropy be incorporated into creative craft practice? To consider these questions, we need to look at examples of contemporary craft collaboration.

8 For example, the Indonesian Fair Trade cooperative Threads of Life claims on its website that it 'encourages weaving communities to revive techniques of weaving and natural dyeing that are in danger of disappearing.' http://www.threadsoflife.com/revitalizing.asp Accessed 30 October 2009. 
craft + design enquiry

\section{The field}

The field of world craft is extremely broad. For the purposes of this exercise, we will not focus on the purely philanthropic world of craft. There is a wide range of NGOs that are funded to assist poorer communities by developing their craft practices. This includes creative enterprises like Upasan, the design studio in Auroville, India, which assists poor rural women, including those affected by the 2004 tsunami. Their products such as the Tsunamika are targeted at Western corporations seeking to demonstrate a positive engagement with the world. ${ }^{9}$

The cases we are examining involve an element of creative partnership between designers and artisans. These can be read critically according to a basic notion of equity ${ }^{10}$ in which we expect symmetry in opportunity between the two parties. By exploring the structure of their operations, we hope to move towards the development of critical principles for understanding alternative paradigms for world craft. Of particular concern is the relative capacity to determine the nature of the collaboration from the finished work.

\section{Cases}

\section{Sara Thorn ${ }^{11}$}

There are a number of Australian craft enterprises that have followed the path of manufacturing in the decision to outsource their production to Asia. The Melbourne-based textile designer Sara Thorn has a history of working with traditional artisans. Her 2003 touring exhibition Dreams of a Golden Thread included work made in collaboration with the lban weavers of Sarawak, Ari hand embroiderers of Kutch, textile block printers of Kutch and Jacquard weavers of Italy. Thorn's own personal motif of the mermaid appeared throughout the different craft media in a hybrid manner. The textiles made by the traditional Iban artisans featured Thorn's motifs, but in a characteristic Ikat style.

While an important platform for the development of Thorn's work, the exhibition did not delve deeply into the perspective of the makers. There was some discussion about the impact of Christianity among the lban as a factor in opening them up to the possibility of non-traditional designs. This could be read either

9 On the other hand there are global craft enterprises that have a reverse interest in the market of the poorer countries. Infamously, the British replaced hand-spun cotton products in Indian with milled textiles from north England. In the 20th century, the Dutch textile company Vlisco has been designing cloths for the African market.

10 One measure of such symmetry is Kant's categorical imperative, "Act only according to that maxim whereby you can at the same time will that it should become a universal law." (Kant, 1993, p.30)

11 Information about Sara Thorn was sourced from interviews on 17 March 2009 and 16 March 2010. 
as a means of exploiting existing cultural dislocation or as a way of stimulating a craft practice that had lost its traditional religious base. But there was little in the exhibition that engaged with the impact of Thorn's commissioning.

Subsequently, Thorn's work has focused on a more sustainable retail vehicle for world craft. She conducted research in India towards the best means of developing an ongoing engagement with traditional crafts. With architect Piero Paolo Gesualdi, she developed the WorldWeave enterprise to retail her designs that are manufactured in India using traditional skills. Rather than use village-based artisans, Thorn decided to engage with the newly established craft factories in Delhi and Amristar. In Delhi, she was able to have her cushion designs machine embroidered in the traditional Ari technique from the Kashmir. Her designs were influenced by circus tattoos from Egypt and Indonesia.

Thorn's commission raises some difficult questions about craft in a contemporary setting. As increasing numbers of villagers migrate to expanding cities in countries like India, it is inevitable that many of the crafts will gradually shift to an urban setting. In terms of the 20th century humanism of Octavio Paz, this represents a distinct loss: craft is no longer embedded in the natural rhythm of rural life. In the factory, craft becomes a mechanised process that can be turned off and on with the whistle.

But there is a more positive perspective. These factories do provide some means by which the craft techniques can be maintained and artisans employed. The factory setting facilitates commissions like Thorn's which can be conducted on a much more transparent level than when they rely purely on personal trust. Communication occurs mostly in black and white on paper, rather than through conversations that are vulnerable to mistranslation. Factory production can be seen as a way of adapting craft to modern reality, rather than artificially preserving it in museums or tourist villages.

From a traditional craft perspective, the use of machines to embroider designs would be seen negatively as a loss of the handmade engagement with process. Yet, here such craft idealism comes up against the issues of global justice. It can be argued that fewer non- Western people, particularly the young generation, are content with repetitive manual labour. If its appeal to Western markets is that the handmade is good for the soul, then why are not the consumers learning to make their products themselves? If the alternative is for traditional handmade techniques to die out for lack of interest by the young generation, then it may be necessary to accept the use of power tools. Given this, one likely effect of the factory is to remove the artisans further from creative participation in the production process. This need not be inevitable, but the outside designer would need to actively circumvent the hierarchies that normally separate management from labour in a factory setting.

The WorldWeave product allows Thorn to develop her designs at a scale appropriate for retail market, while still maintaining reference to craft processes. However, degree of creative involvement from the producers seems to have 
been reduced from that in her touring exhibition. ${ }^{12}$ It could be argued that the degree of craft process in the exhibition would be challenged to fulfil the large and time-dependent orders required by retail.

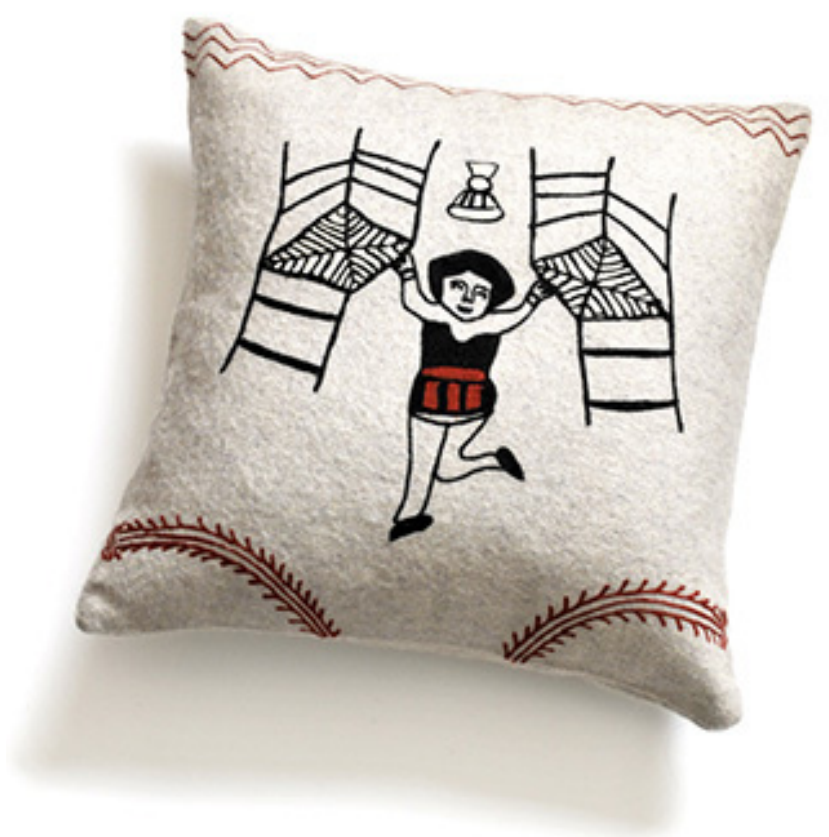

Plate 1: Sarah Thorn for WorldWeave, Acrobat Cushion, 2009, wool felt, hand embroidered.

Photograph: James Widdowsen.

\section{polly\&me ${ }^{13}$}

The paradigm developed under the brand polly\&me explicitly attempts to involve artisans in product development. Fashion designer Cath Braid and

12 While in Thorn's case, objects are being produced for a Western market, there are increasing cases of Australian designer-makers working for companies that service what are today called the emerging economies. These include Karl Millard (India), Jonathan Baskett (Mexico) and Janet deBoos (China). The narrative at play here is of countries that previously were seen as places to have Western-designed products cheaply manufactured. Now, there are growing capacities in design as well as manufacturing. Western designer-makers are being invited in to provide expertise in the development of these industries. This poses a challenging question of whether this will eventually phase out, as this knowledge is finally passed on. Alternatively, it could be that there will still exist a capacity integral in Western culture that will always be needed in manufacturing in the Global South. 13 Information about Polly\&Me is sourced from interviews with Cath Braid (January 2, 2009) and Ange Braid (April 14, 2009), catalogue Gup Shup: The domestic, the narrative and cups of chai, website (http://www.pollyandme.com), Summer (2006) and transcripts of interviews with participants conducted after the exhibition. 
communications graduate Kirsten Ainsworth developed a business titled Caravana, which worked with women embroiderers living in the north-west frontier region of Pakistan. In 2003, Braid and Ainsworth lived in the Chitral valley, where they attempted to develop a fashion line that incorporated embroidered designs from local women.

The two westerners faced initial resistance from the men in the community, who were strict Sunni Muslims, but they gained local support through an NGO, AKRSP (Aga Khan Rural Support Program). With this local support, they eventually established 10 work centres, each with a female manager and employed approximately 500 women in total. The designs they embroidered combined traditional patterns and the format provided by Caravana. The first collection debuted in 2004 during Sydney Fashion Week and the second was launched in Melbourne in 2006. Caravana as a 'label with a conscience' managed to secure major stockists for their product.

However, Caravana disbanded after this initial success. Together with her sister Ange, Cath Braid established polly\&me, which attempted to continue this work in an alternative way. During the 2007 Smartworks Symposium at Powerhouse Museum, Cath Braid was impressed with the idea conveyed by a potter working in Ernabella Arts Centre that women artisans had an inherent creativity. She was inspired by this to find ways of including more creative involvement by the women weavers. They then expanded production to include the creation of art works; she developed workshops to help the women develop their own designs. Assisted by a Lebanese aid worker Rolla Khadduri, they conducted workshops over winter in 2008 featuring use of a digital camera and intuitive drawing exercises. Inspiration came from immediate sources like children's games and consumer packaging. In the end, thirty women were involved in the production of 23 textiles. There was also a series of button pieces with words in Arabic that was produced by a larger group of 250 women.

With support from the British High Commission, these works were exhibited in Islamabad and Karachi. Most sold. The embroideries included stories of everyday life in Chitral, such as the game during Eid when children battle with eggs, and a local figure Sultan the Sitar- Player. In the gallery, the works were exhibited at a distance from the wall so that visitors could read a version of the story on the other side.

A catalogue was produced that highlighted the narratives and a report was written that reflected on the women's responses to the show's success. Their responses were positive, including pride at the exhibition's coverage on satellite television and pleasure at the extra income from sales that would help with their family. ${ }^{14}$ While this supports the project, it may have been difficult for the

14 For example, in an interview with one of the artists, she says 'I felt a certain confidence in me for the first time. Meeting such high level people who were there to see our work was something we had not even thought of in our wildest dream, it was like that I was dreaming. Our prayers are always with Cathy and Rolla, all this would not have been possible without their sincere efforts.' 
women to express any problems as this may have seemed inhospitable and ungracious. What seemed important in this case is that the women were asked, which implied that their own views of the project were a part of its success.

While the involvement in art works provides greater participation for the women of Chitral, it is in danger of being seen as a one-off gesture that doesn't provide any ongoing work. To deal with this problem, polly\&me plan to develop a project each year in Pakistan, including an artwork project to raise awareness about HIV among truck drivers. To complement the art work, polly\&me continue to produce the bag accessories.

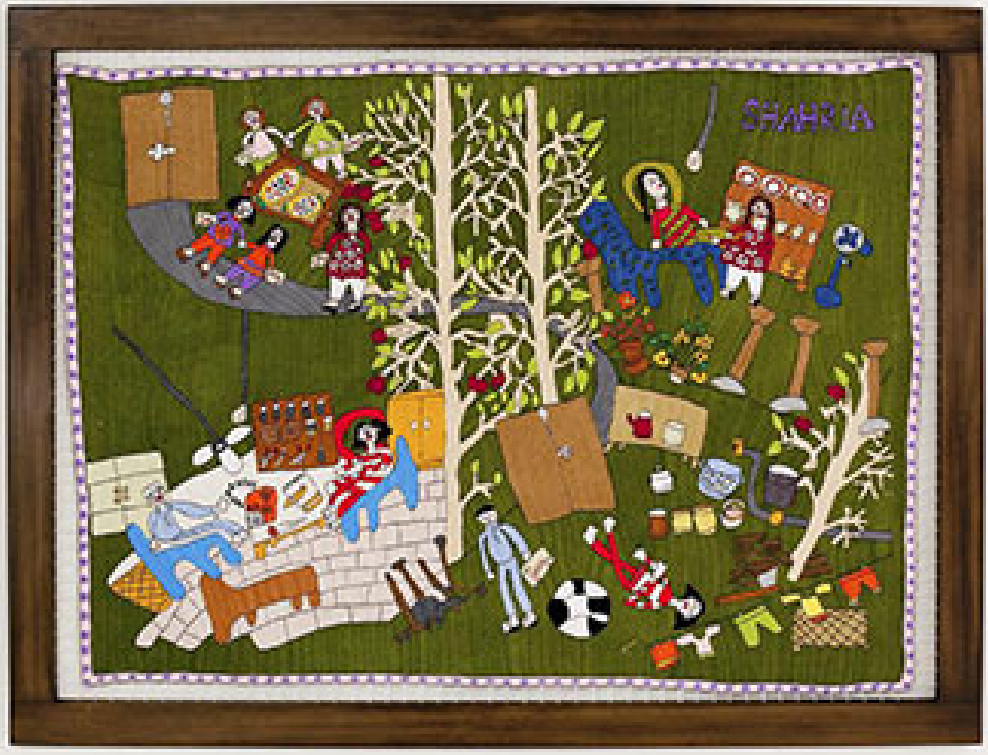

Plate 2: Shehria and Rahmat, The Bet, 2009,cotton embroidery. Based on a story about a girl who broke her arm while trying to win a bet.

Photograph: unknown.

\section{Martina Dempf ${ }^{15}$}

One recent area of craft collaboration is in the discipline of anthropology. This is part of a more reciprocal understanding of anthropology in which there is a perceived obligation on the behalf of the visitor to make transparent the nature of their transaction with the community under study (Grimes \& Milgram, 2000). The development of a craft product also entails engagement with issues of tradition, authority and aspiration that assist in a better understanding of the community dynamics. 
Martina Dempf is a jeweller based in Berlin who studied with the German modernist jeweller Rheinhold Reiling. During her course, she took off half a year to work as a volunteer in a project by Swiss Aid based in Lesotho (Southern Africa) with a jewellery company called the Royal Crown Jewellers. On becoming a jeweller, she returned to Africa where she travelled through most of the continent. On the basis of that experience, she decided to study anthropology, which resulted in an MA thesis at the Free University of Berlin ('People Adorned: The Material Culture of the Toposa in Southern Sudan and the Turkana in Northern Kenya').

During a field trip in 1986, she visited Rwanda, where she saw baskets being made that she thought could be transformed into jewellery. In 2007, she approached GTZ (German Technical Co-operation) and was invited to work with a group of 40 women in Butare who were organized in a crafts association (Rwanda Art). By this time, they seemed disconnected from the basket-making tradition. It was up to Dempf to first recover the lost tradition. Dempf found a thesis on traditional Rwandan crafts from Berlin Museum of Ethnology from which she was able to re-invent traditional designs. Together with the women, they created a collection of grass jewellery. The women created the grass elements from papyrus and sisal. Later, in a separate development, Dempf developed her own version of this jewellery which incorporated the elements made by Rwandan women into a most Western silver casing.

Rwandan basketry is recognized for its strong designs combined with delicate structures (Sullivan, 1978). Traditionally, baskets were made for the royal court. The traditional craft had been challenged by both the decline of the royalty and the arrival of Western goods, accompanied by the omnipresent plastic bags. No longer the only available utensil for containment, the craft of basketry faces the challenge of finding other markets. The recent violent history in Rwanda has not been encouraging for tourists. Given its mobility and universality, jewellery offers the opportunity for Rwandan craftspersons to find an alternative audience.

As a result of these workshops, the Rwandan women have developed a range of jewellery that is now sold online through the cooperative website Rwanda Art: Union of the Art Cooperatives. ${ }^{16}$ This jewellery does not have the silver elements, which makes them cheaper but also less durable.

Dempf continues to source components for her jewellery from Rwanda, though she is also engaged in other exchanges with Laos and Cambodia. Her project has further developed the collaboration paradigm. The training necessary for the creation of the components has not only developed a commissioning capacity in the community of Rwandan women to service a German jeweller, it has also given them the opportunity to market their own products directly. Of course, there is still a large discrepancy in the kinds of markets that each are servicing. And there is little information about how successful this enterprise is for the

$16 \mathrm{http}: / /$ www.rwanda-art.com Accessed 29 October 2009, though it has not been updated since 2006. Rwanda Art has an exhibition and a shop in Butare presenting only locally made products. The local art coordinator also organises the production, so that the women are able to work at home. 
women involved. Notwithstanding these limitations, Dempf's model presents an important paradigm for how craft might be produced collaboratively across the global divide.

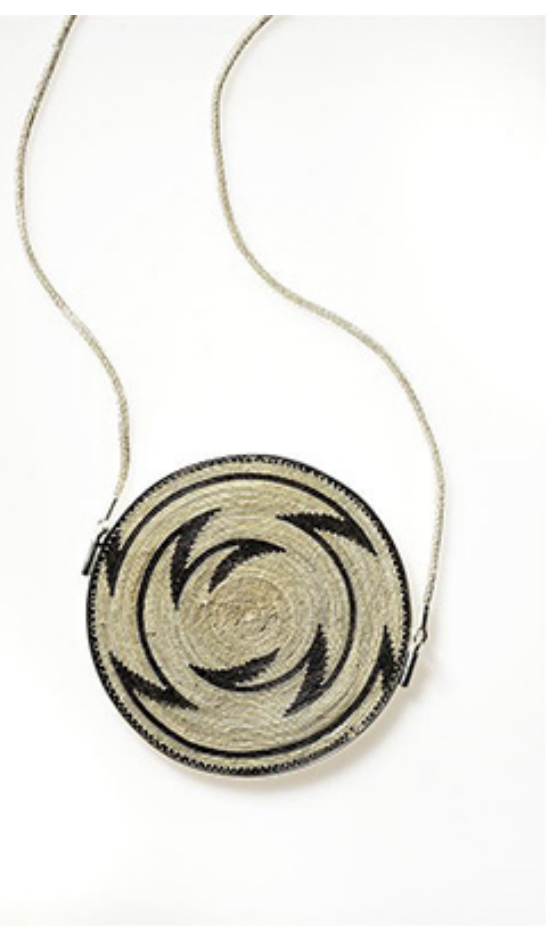

Plate 3: Artists of Butare, Rwanda, Untitled jewellery, 2009, natural fibres. Made in cooperation with Martina Dempf, Germany.

Photograph: Sebastian Ahlers.

\section{Conclusion}

The three cases we have examined all involve an element of outsourcing in the craft production process. Within this, they vary in the degree of agency exercised by non- Western artisans. Forms of participation include straight commissioning (Thorn), creative development (polly\&me) and business development (Dempf). Given this imbalance, Dempf's model seems to be the one which offers greatest independence for artisans.

But there are limitations. We measure levels of participation against an ideal situation of equality, in which both designer and artisan have reciprocal powers. Each would be equally capable of initiating projects and defining their meaning. It is clear that none of the three cases we have looked at reach this ideal. In all projects, the ultimate agency lies with the Westerner. The designer is always the one who initiates the project, even if it is on behalf of the artisan. But we need to take this limitation in context. We need to consider the global inequity that forms 
the context of these relationships. Individual designers are not able to reverse the lie of the land that constrains reciprocity between Global North and South. Their work can be critiqued against standard contemporary practice rather than the distant horizon of total equality.

In terms of creative development, there are different readings dependent on the aesthetic paradigm. From an individualist perspective, Thorn's outsourcing seems most consistent with her stylistic development. But from an alternative model of relational aesthetics (Bourriaud, 2002; Murray, 2009), the models established by polly\&me provide a more participatory purchase on the creative process.

We can then conclude that craft outsourcing does potentially offer a significant development in modern craft. It continues the role of craft as a bridge between traditional and modern cultures, but with increasing awareness of the political dimension in creative expression. As the focus of primitivism moved from masks to people, contemporary craft- design collaborations reflect a more active role for the non-Western artisans. They are no longer mere performers of difference, but participants in cooperative exhibition and retail ventures.

But there is a long way to go. At this stage we must admit a limitation in possibility of critical analysis. All the information is mediated through the Western partners in this process. We do not have the kind of information that would conclusively negate criticisms that such projects somehow manufacture non-Western participation in order to satisfy a Western need for positive reinforcement of their culture. This is not simply a matter of giving makers a questionnaire to fill out. Given the traditions of hospitality, we cannot take for granted that informants would prioritise formal truth above the need to save face.

To obtain such information is not easy. The wide difference in education between designer and artisan constitutes a difficult barrier. With lack of education comes not only less ability to engage in authoritative Western discourses, such as scholarly articles. But it also lessens confidence in one's experience against the better-informed views of outside designers.

What is needed now is a mechanism for authenticating the nature of participation in craft outsourcing. This applies particularly where the product is being presented as authentically handmade, such as in the cases discussed here. This would provide a means of countering the scepticism about the staging of difference for the purpose of the Western gaze. The development of a forum for the voice of the artisan is a critical step in the potential of world craft to develop into a vehicle for global dialogue.

The next step is to test the effectiveness of a formal structure that represents the point of view of the artisan. Such a structure should not be constructed solely at the consumer end of the conversation, but involve representative 
bodies at the community level of the artisan as well. As world craft production becomes increasingly collaborative, there is increasing need for tools by which such collaboration can be verified.

\section{Bibliography}

Araeen, R. 1987. From primitivism to ethnic arts. Third Text, 1, pp. 6-25.

Auger, P. Devinney, T. \& Louviere, J. 2007. Measuring the Importance of Ethical Consumerism: A Multi-Country Empirical Investigation. In P. Madsen and J. Hooker ed. Controversies in international corporate responsibility. Charlottesville, V.A.: Philosophy Documentation Center.

Bourriaud, B., 2002. Relational aesthetics. Paris: Les presses du réel.

Chossudovsky, M., 2003. The globalization of poverty and the new world order. Pincourt, Québec: Global Research.

de Waal, E. 2002. Altogether elsewhere: The figuring of ethnicity. In P. Greenhalgh ed. The persistence of craft: the applied arts today. London: A \& C Black.

Feld, S. 2000. A sweet lullaby for world. Public Culture, 12(1), pp. 145-171.

Foster, H. 1985. The "Primitive" Unconscious of Modern Art. October, 34, pp. 45-70.

Goldwater, R. 1986. Primitivism in modern art. Cambridge, Mass.: Belknap Press.

Grimes, K. \& Milgram, B. 2000. Artisans and cooperatives: Developing alternative trade for the global economy. Tucson: University of Arizona Press.

Hareven, T. 2003. The silk weavers of Kyoto: family and work in a changing traditional industry. University of California Press.

Kant, I. 1993. Grounding for the metaphysics of morals. London: Hackett.

Leach, B. 1978. Beyond East and West. New York: Watson-Guptill Publications.

Leach, B. 1976. A potter's challenge. London: Souvenir Press.

Lyon, S. 2006 Evaluating fair trade consumption: Politics, defetishization and producer participation.

International Journal of Consumer Studies, 30(5), pp. 452-464.

MacCarthy , F. 1994. William Morris: A life for our times London: Faber.

Morris, W. 1980. How I became a socialist. In A. Briggs ed. News from nowhere and selected writings. Harmondsworth: Penguin. 
Murray, K. The relational aesthetics of Vipoo Srivilasa and Rirkrit Tiravanija. Art \& Australia, 47(2).

Parkins, W. \& Craig, G. 2006. Slow living Oxford: Berg.

Paz, O. 1974. In praise of hands: Contemporary crafts of the world. Toronto: World Crafts Council.

Petrini, C. 2005. Slow food revolution New York: Rizzoli Inc.

Scrase, T. 2003. Precarious production: Globalisation and artisan labour in the Third World. Third World Quarterly, 24(3), pp. 449-461.

Sullivan, M. 1978. African grass and fiber arts. African Arts, 12(1), pp. 91. 